\title{
Fundamentos Filosóficos de la propuesta de Virginia Avenel Henderson
}

Lic. Margarita Delgado Rubio, Lic. Carlota M. Hernández Rosales* y Mtra. Rosa Ma. Ostiguín Meléndez** *Alumnas del segundo semestre del programa de Maestría en Enfermería ENEO-UNAM

** Tutora del Programa de Maestría en Enfermería ENEO-UNAM

La propuesta filosófica de Virginia Henderson define la función de la Enfermera en el cuidado del paciente, basándose en la valoración de las 14 necesidades, y el grado de dependencia e independencia que tenga para la satisfacción de las mismas. Analizar los orígenes teóricos de la propuesta permitió reconocer que no cuenta con los requisitos para ser catalogada como modelo o teoría. Sin embargo, conocer las principales influencias y experiencias que llevaron a Henderson a elaborar su propuesta filosófica permite comprender los fundamentos de sus conceptos y el nivel de desarrollo en que se encuentra dentro de la estructura del conocimiento.

PALABRAS CLAVE: Henderson, modelos, teoría, Enfermería.

\section{Abstract}

The Virginia Henderson philosophic proposal defines the nurse's work in terms of patient care, based upon the value of the 14 needs. Also the dependence and independence level that the patient has for the satisfactions of his/her needs. Analyzing the theoretical origins of the proposal showed that they do not have the requirements to be a model nor a theory. However, knowing the main influences and experiences that took Henderson to create her philosophic proposal allowed the understanding of the concepts bases and the development level of the knowledge structure.

KEY WORDS: Henderson, models, theory, nursery.

\section{INTRODUCCIÓN}

Generalmente cuando se piensa en los modelos y teorías de Enfermería, viene a la mente -entre otras- la de Virginia Henderson. Sin embargo al hacer una revisión más profunda se reconoce que no cumple en estricto sentido con estas categorías y llanamente se ofrece como una propuesta filosófica.

Lo anterior emerge a partir de realizar una revisión documental sobre los orígenes "teóricos" de esta propuesta, en el marco del seminario del Programa de Maestría en Enfermería.

Los fundamentos de la propuesta de Virginia Avenel Henderson representan una visión personal de la función de la Enfermera, originada por sus influencias y experiencias recibidas durante su trayectoria profesional.
El presente artículo tiene como finalidad analizar los orígenes de la propuesta filosófica de Virginia Henderson y mostrar algunos personajes que influyeron en la elaboración de las definiciones y conceptos que le dan cuerpo a la propuesta.

Para ello se hace una revisión de los antecedentes de Henderson, para posteriormente realizar un viaje a través de los personajes más influyentes en su propuesta.

\section{ANTECEDENTES}

Henderson nació en Kansas City, Estados Unidos el 19 de Marzo de 1897, siendo la quinta de ocho hermanos. Vivió en Virginia a partir de 1901 ya que su padre ejercía la abogacía en Washington D.C. En el Verano de 1918 a los 
20 años Henderson Leyó sobre la Army School of nursing de Washington D.C. a la cual ingresa por intercesión de su padre y se recibió como Registered Nurse después de 3 años de estudio, y en 1929 obtuvo el grado de Master en la Universidad de Columbia y de 1948 a 1953 realizó la revisión de la $5^{\mathrm{a}}$ edición del texbook of the principles and practice of nursing de Berta Harmer publicado en 1939.

En 1955 da su propia definición de Enfermería y dirige el proyecto Nursing Studies Index. En 1966 publica su obra the Nature of Nursing en donde describe su concepto sobre la función única y primordial de la Enfermera. En la primera edición de su libro "Principios básicos de Enfermería" (1971), da a conocer los componentes básicos de los cuidados (14 necesidades), refiriendo en forma sencilla las necesidades fundamentales de cada persona comunes a todos los individuos y a todas las edades. Obtuvo nueve títulos doctorales honoríficos de diversas Universidades y en 1988 recibió mención de honor por sus contribuciones a la investigación, la formación y la profesionalidad en la Enfermería. El 30 de Noviembre de 1996 fallece de muerte natural a la edad de 99 años.'

La propuesta de Virginia Henderson se considera filosofía debido a que no permite organizar los conceptos y definiciones para lograr una relación entre sí con el fin de proporcionar una estructura de naturaleza sistemática.
La falta de organización de conceptos no permite tener un fundamento para las acciones de Enfermería, que explique en forma sistemática los métodos de atención y prediga los resultados. ${ }^{2}$

\section{INFLUENCIAS}

Después de la revisión documental se encontró que la filosofía de las 14 necesidades de Henderson reconoce personajes que fueron influencias determinantes para la elaboración de sus conceptos y definiciones (Ver fig. 1).

Henderson recibe su primer influencia de Annie W. Goodrich quien contemplaba a la Enfermería como "una actividad social mundial", una fuerza creativa y constructiva en la sociedad y daba un valor importante al "significado ético de la Enfermería". ${ }^{3}$ A partir de ella se infiere que Henderson elaboró el concepto de autonomía en la práctica liberándola de la imagen de anexo de la medicina y ponderando el valor del trato humano que se da al paciente. Posteriormente, cuando Henderson se desarrolla en una Institución Psiquiátrica, aprecia la importancia de las relaciones humanas e integra sus conocimientos para conceptualizar el cuidado individualizado de Enfermería.

Carolina Stackpole y Jean Broadhurst ambas profesoras de la Universidad de Columbia, basaban su enseñanza

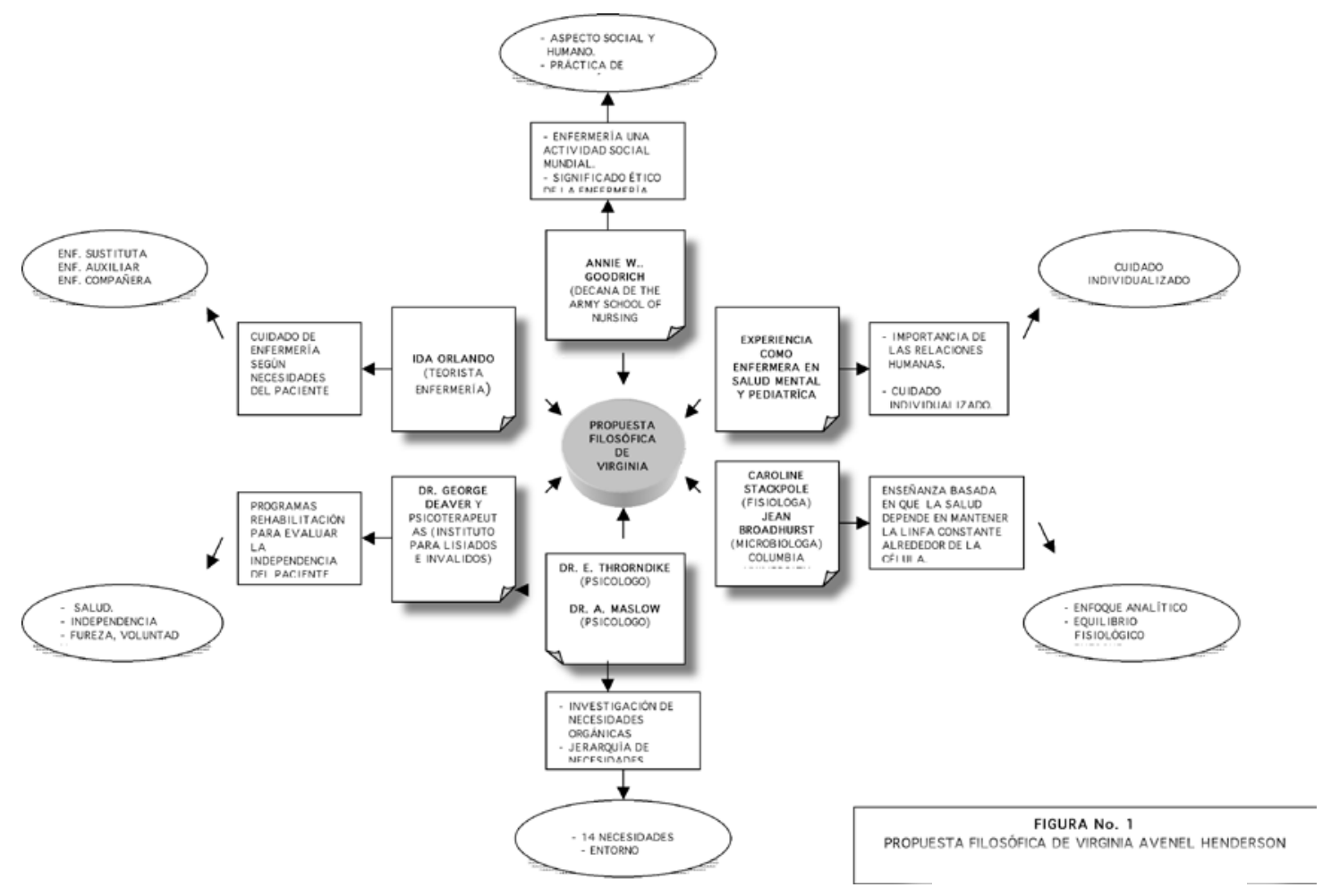


de la fisiología en el principio que la salud depende de mantener la linfa constante alrededor de la célula. De ellas Henderson adquiere el enfoque analítico de todos los aspectos de la asistencia y del tratamiento, considerando que la definición de Enfermería debe de incluir el principio del equilibrio emocional (psicológico) y que este es inseparable al fisiológico.

Del psicólogo Edward Thorndike de la Universidad de Columbia quien elaboró las leyes del aprendizaje, del ejercicio y la del efecto*, a partir de estos principios se deduce que Henderson retoma el valorar al individuo en cuanto a que tiene o no voluntad, conocimiento y fuerza para satisfacer sus necesidades individuales y detectar oportunamente la insatisfacción de las necesidades con el fin de saber el tipo de intervención que requiere el paciente (de suplencia, como auxiliar o como compañera) para obtener o recuperar su independencia. A partir de lo anterior Henderson consideraba que los miembros del equipo de salud deberían de considerar a la persona que atienden, la figura central de su actuación y comprender que su función principal es la de cooperar a la recuperación de la salud con la satisfacción de sus necesidades y reconoció también la importancia de mantener al paciente en un entorno lo más parecido al que se desenvuelve continuamente con lo que intenta darle un enfoque integral a los cuidados de Enfermería. ${ }^{4}$

Aunque Henderson no menciona influencia directa a A. Maslow se deduce que tuvo cierto grado de participación ya que como existieron en 1936 como profesores en la Universidad de Columbia. Maslow jerarquizó las necesidades considerando que algunas prevalecen sobre otras y parecería que de aquí Henderson enunció las 14 necesidades.

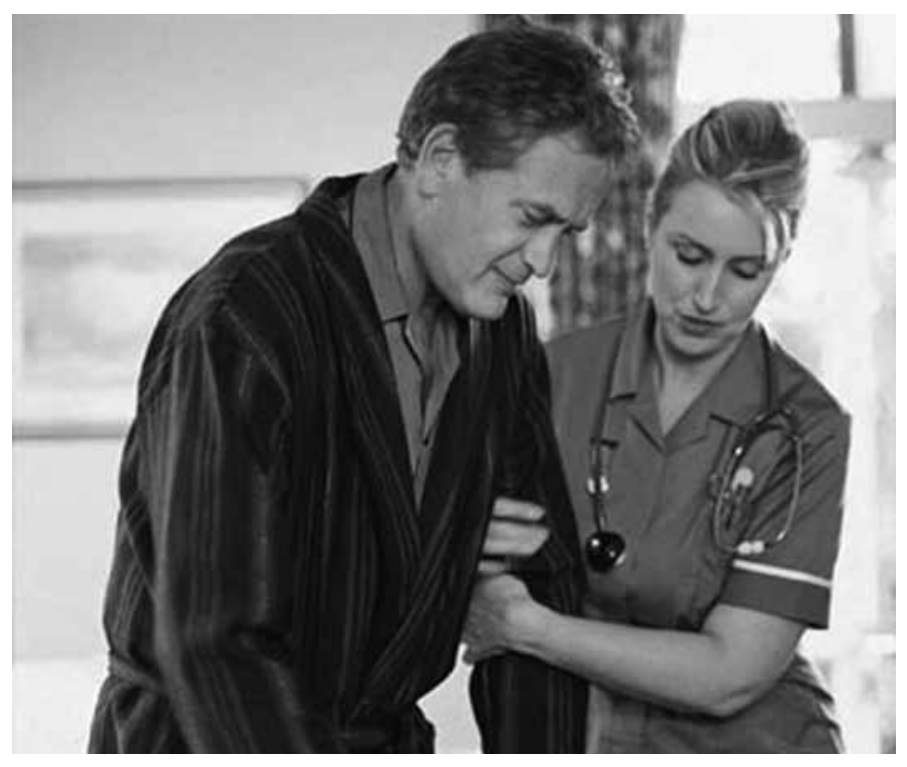

Además de estas influencias, Henderson vió el trabajo George G. Deaver fisioterapeuta que realizaba programas cuyo objetivo era reafirmar la independencia del paciente misma que retoma como sinónimo de salud. Esto influyó en Henderson para definir su concepto de persona en donde quizás también lo retomó para justificar que el paciente no requería siempre una intervención de suplencia total por parte de Enfermería, al ver que el proceso de rehabilitación implicaba grados diferentes de ayuda. ${ }^{5}$

Ida Orlando conocida como Pelletier, Enfermera psiquiatrica y reconocida teórista en la disciplina, mencionó que la Enfermería más eficaz implica una observación e interpretación continua del comportamiento del paciente, mismo que el que aprueba la interpretación que hace la Enfermera de su necesidad esta juzga la eficacia de la acción según el grado de satisfacción de la necesidad por parte de la persona. Parecería que Virginia Henderson fundamentó su definición de la relación Enfermera paciente en donde deja claro la importancia de una adecuada valoración de las capacidades y deficiencias reales del paciente para satisfacer sus necesidades. ${ }^{6}$

Es evidente que las experiencias que Henderson tuvo en su trayectoria profesional fueron plasmadas en sus conceptos y definiciones, los cuales hasta hoy no han sido modificados, pero si utilizados frecuentemente como guía en la práctica profesional de Enfermería y en la elaboración de programas educativos.

En sus definiciones Henderson refiere que la Enfermera debe tener amplios conocimientos en las ciencias biológicas y sociales para comprender en parte, qué está pasando con el paciente y así hacer posible la valoración de las necesidades fundamentales de la persona. Sin embargo también utiliza una interesante frase, "meterse en la piel del paciente para saber qué es lo que necesitan", es decir empatía. Esta frase tiene el gran significado de considerar a la persona no sólo como un ente biológico, sino con otras "sensaciones o necesidades" que no son observables ni mesurables como las biológicas. Son estas necesidades las que hablan de la interioridad de las personas las que le dan el sentido de filosofía humanista

\section{CONCLUSIONES}

La revisión de los orígenes de la propuesta filosófica de V. Henderson lleva a pensar que la formación académica y experiencia profesional fueron determinantes para el tipo de pensamiento que la autora muestra en su obra.

Se visualiza en su propuesta la fuerte influencia que ejercie- 
ron en ella reconocidas Enfermeras, psicólogos conductistas, fisioterapeutas y fisiólogos quienes le permitieron ver que el individuo es la integración de cuerpo y mente en el cual confluyen factores positivos y negativos determinantes en la satisfacción de las necesidades fundamentales.

Al margen es pertinente comentar que la bibliografía localizada sobre la propuesta de Henderson es extensa y redundante y se desarrolla generalmente en torno a la valoración en el marco del Proceso de Atención de Enfermería.

La revisión de los orígenes de la propuesta de Henderson permitirá a quienes se inician en el estudio de los modelos y teorías, reconocer que si bien, la propuesta de Henderson no cumple con los requisitos para ser modelo y/o teoría, si logra con claridad plantear la función de Enfermería con un sentido humanista. Sea este documento solo un ejercicio preliminar para reflexionar en las raíces de los modelos.

\section{NOTA}

La ley del efecto se retoma de manera importante en la Psicología del aprendizaje y sostiene que las conductas aprendidas son las que satisfacen un determinado impulso, positivo o negativo, es decir que las que satisfacen una necesidad o evitan un peligro, mientras que las conductas que impiden la satisfacción de una necesidad del organismo o que le atemorizan no son las aprendidas.

\section{REFERENCIAS BIBLIOGRÁFICAS}

1 Marriner TA. Modelos y teorías en enfermería. Ed. Harcout Brace. $4^{\mathrm{a}}$ ed. Madrid; 1999. p 100

2 Fawcett J. Analysis and Evaluation of Contemporary Nursing Knowledge. Nursing Models and theories. Davis Company Philadelphia, 2000 p 4

3 Herderson AV. Reflexiones 25 años después en: La naturaleza de enfermería. Ed. Mc-Graw-Hill. Madrid, 1994. p 10

4 Thorndike, Edwuard L. (1874-1949). Monografías.com. disponible en: http://www.psicoactiva.com/bio/bio_20.htm . México, 2006. p 1-2

5 Henderson AV. Los primeros 90 años. Ed. Mason. Barcelona, 1996. p 52

6 Henderson. La naturaleza... op.cit. p 17

7 Henderson. La naturaleza... op.cit. p 20

\section{DIRECCIÓN PARA CORRESPONDENCIA}

Margarita Delgado Rubio: dimeadamor@hotmail.com

Carlota M. Hernández Rosales: tota_meher@hotmail.com

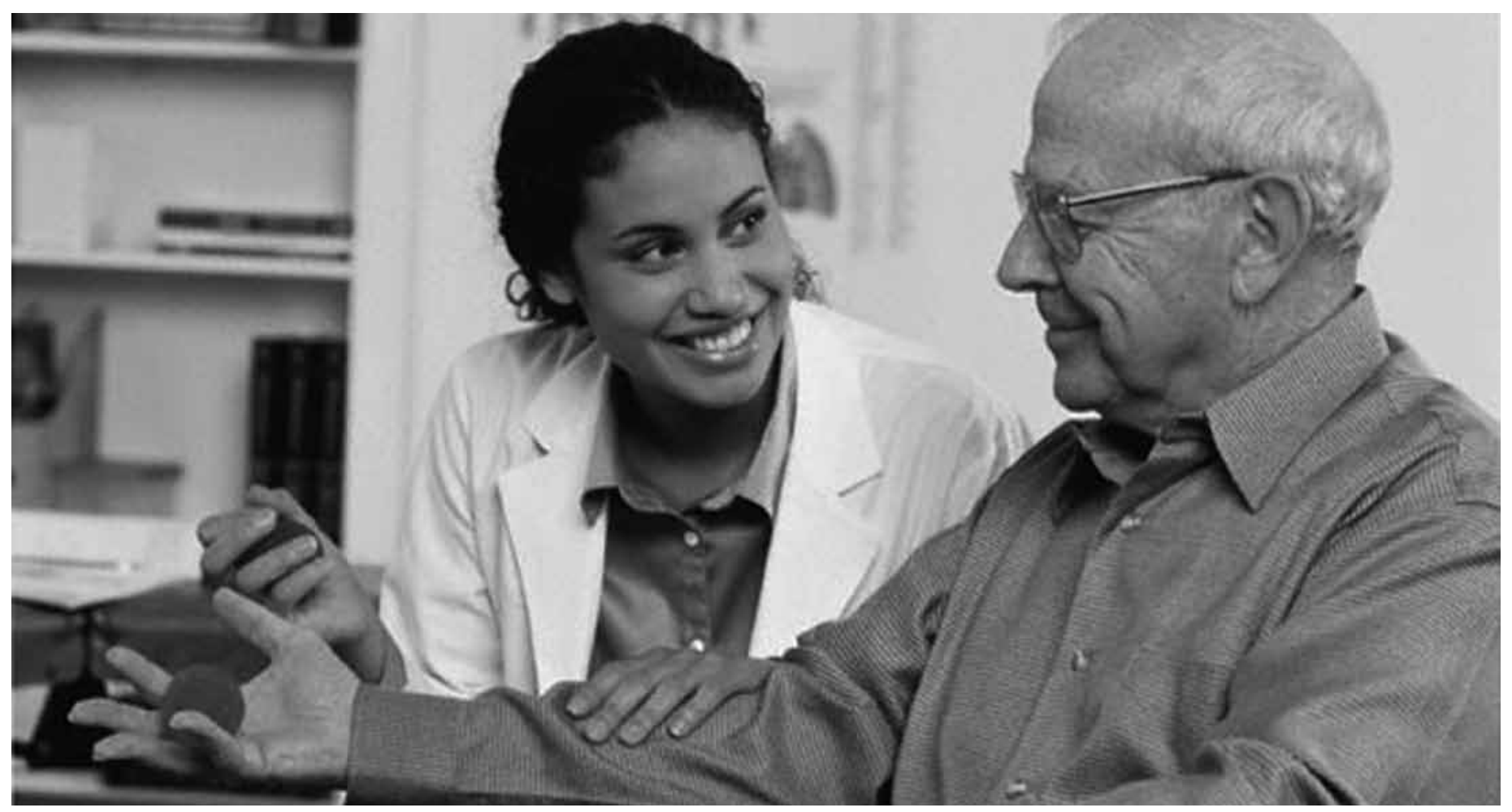

